\title{
PROJETO DE IMPLANTAÇÃO DO PLANO MUNICIPAL DE ARBORIZAÇÃO URBANA DE AGUDO: INSTRUMENTO DE PARTICIPAÇÃO POPULAR, GESTÃO E EDUCAÇÃO AMBIENTAL
}

\author{
CARLOS RUDOLFO PAUL', CLÁUDIA BERNARDINI², \\ JANETE VANDA DUMKE ${ }^{3}$, MARCIANO LOUREIRO FILHO ${ }^{4}$ \\ 1 - Geógrafo, estagiário do Depto. de Meio Ambiente da Prefeitura de Agudo. Autor, carlosrpaul@hotmail.com, \\ 2 - Bióloga, Fiscal Ambiental do Departamento de Meio Ambiente da Prefeitura de Agudo. Autora, \\ claudia.ambiente@hotmail.com, \\ 3- Engenheira Florestal do Departamento de Meio Ambiente da Prefeitura de Agudo. Autora, \\ jane.floresta@hotmail.com \\ 4- Engenheiro Florestal da EMATER/RS- ASCAR
}

Palavras-chave: arborização urbana, gestão ambiental, educação ambiental.

Ao longo da construção de uma gestão ambiental mais participativa, o poder público municipal de Agudo/RS defrontava-se com o apelo da população pela modificação na forma como tratava da arborização urbana. Pesquisas de satisfação, audiências públicas para a montagem do novo Plano Diretor e por fim manifestações de lideranças no Seminário Ambiental para multiplicadores, em 2009, apontavam para a necessidade da criação de um Plano de Arborização Urbana. Foi aí que, com participação de lideranças comunitárias e entidades governamentais, em agosto de 2009 iniciou-se o seu planejamento, em fevereiro de 2010 uma equipe de funcionários recebeu treinamento sobre poda, e no dia 23 de março de 2010 foi lançado o Plano de Arborização Urbana de Agudo, em um evento chamado "Consulta Pública do Plano de Arborização Urbana de Agudo", onde a população urbana teve oportunidade de conhecer as metas do projeto e decidir pela área prioritária de implantação, bem como as espécies que deveriam ser utilizadas. Para este momento foi realizado diagnóstico da situação atual e criada uma listagem de espécies indicadas para serem implantadas em passeios públicos com fiação elétrica alta, baixa ou sem fiação. Foram apresentados também os períodos destinados à poda e ao plantio, sendo estes de responsabilidade da Prefeitura Municipal. Em 2010, foram plantadas 70 mudas (cujo valor individual foi de $R \$ 18,00$ ) e colocadas as devidas proteções de tela e ferro (ao custo de $\mathrm{R} \$ 70,00$ cada). Para 2011 está previsto o plantio de 120 mudas, com proteções colocadas. Foi editada uma cartilha com orientação sobre o manejo correto das árvores urbanas, poda, escolha de espécies e problemas causados pela má condução da arborização. Esta foi lançada no Seminário Ambiental Municipal 2011, dia 01 de junho, e distribuída à todos os alunos das escolas do meio urbano, garantindo assim ampla divulgação das informações. O projeto terá continuidade nos próximos anos e está previsto ainda neste ano uma reunião de avaliação e recondução, com a população.

\section{Introdução}

Ao longo da construção de uma gestão ambiental mais participativa, o poder público municipal de Agudo/RS defrontava-se com o apelo da população pela modificação na forma como 


\section{Revista Eletrônica em Gestão, Educação e Tecnologia Ambiental}

REGET/UFSM (e-ISSN: 2236-1170).

tratava da arborização urbana. Pesquisas de satisfação, audiências públicas para a montagem do novo Plano Diretor e por fim manifestações de lideranças no Seminário Ambiental para Multiplicadores, em 2009, apontavam para a necessidade da criação de um Plano de Arborização Urbana. Com o objetivo de criar um instrumento de planejamento e gestão da arborização urbana municipal, bem como garantir a participação da comunidade nas decisões sobre o tema, em agosto de 2009 iniciou-se a construção do Plano de Arborização Urbana de Agudo, com participação de lideranças comunitárias e entidades governamentais.

As ações sobre o ambiente natural ou sobre o ambiente construído podem afetar a qualidade de vida de várias gerações, pois estão ligadas à melhoria da qualidade do ar, e a aspectos estéticos, desta forma a arborização urbana é um dos fatores mais importantes , (Condesus/UFSM, 2009).

A arborização urbana, em relação às espécies arbóreas, constituem parte da identidade de uma cidade, em seus fatores culturais, estéticos, sociais, econômicos e principalmente ecológicos ao propiciar refúgio e alimento à fauna urbana.

O planejamento urbano municipal, proposto pela Constituição de 1988, tem como meta o crescimento econômico com a necessidade de assegurar a preservação ambiental. Este planejamento deve ser implementado pelas políticas públicas de crescimento urbano ambientalmente sustentável, o qual inclui a manutenção da arborização urbana.

\section{Metodologia}

Metodologicamente, este trabalho é considerado uma pesquisa aplicada, qualitativa, pois busca informações técnicas para a solução de problemas concretos do cotidiano da população. 0 público alvo são os cidadãos residentes na área urbana do Município de Agudo/RS.

Como forma de atender os objetivos do projeto, foram realizadas reuniões com equipe técnica da Prefeitura de Agudo e EMATER - ASCAR/RS juntamente com lideranças voluntárias de entidades civis do município, e posteriormente aberta a toda população.

Através de levantamento prévio da vegetação arbórea existente nos principais logradouros, bem como as distâncias dos principais componentes da área urbana como fiação elétrica, entradas de garagem, recuos das edificações, etc; formaram o "esqueleto" inicial para a decisão de onde plantar, com a participação da comunidade.

\section{Resultados}

Nas reuniões de planejamento foram desenvolvidos os Planos de Ação, que contemplam todas as atividades previstas no decorrer da execução do projeto e foram um instrumento importante de controle e acompanhamento. O Quadro 1 demonstra o resultado final do primeiro Plano de Ação do projeto. 
PAUL et al., v(5), n5, p. 783 - 791, 2012.

Revista Eletrônica em Gestão, Educação e Tecnologia Ambiental

REGET/UFSM (e-ISSN: 2236-1170).

Quadro 1. Plano de Arborização Urbana de Agudo - Plano de Ação 2010

\begin{tabular}{|c|c|c|c|}
\hline $\mathrm{O}$ que & Como & Quando & Responsável/Controle \\
\hline $\begin{array}{c}\text { Diagnosticar os principais } \\
\text { problemas na arborização } \\
\text { urbana municipal. }\end{array}$ & $\begin{array}{c}\text { Saída a campo para } \\
\text { diagnóstico, nas áreas de } \\
\text { maior movimento de } \\
\text { pedestre e carros. }\end{array}$ & Janeiro & $\begin{array}{c}\text { SEAGRIMA } \\
\text { (Secretaria da Agricultura e } \\
\text { Meio Ambiente) } \\
\text { OK }\end{array}$ \\
\hline $\begin{array}{l}\text { Construir propostas } \\
\text { baseadas em } \\
\text { conhecimento técnico } \\
\text { para sanar os problemas; }\end{array}$ & $\begin{array}{l}\text { Definição de ações } \\
\text { relacionadas à, poda, } \\
\text { plantio, proteção de } \\
\text { mudas, escolha de } \\
\text { espécies, espaçamentos, } \\
\text { tudo baseado na legislação } \\
\text { municipal vigente. }\end{array}$ & Janeiro/fevereiro e março & $\begin{array}{c}\text { EMATER- ASCAR/RS e } \\
\text { SEAGRIMA } \\
\text { OK }\end{array}$ \\
\hline $\begin{array}{l}\text { Envolver a comunidade } \\
\text { na tomada de decisões e } \\
\text { ações do projeto; }\end{array}$ & $\begin{array}{c}\text { Definir os momentos em } \\
\text { que a comunidade será } \\
\text { chamada para opinar e } \\
\text { para avaliar. }\end{array}$ & Março & $\begin{array}{c}\text { Comissão da Arborização } \\
\text { Urbana } \\
\text { OK }\end{array}$ \\
\hline $\begin{array}{c}\text { Criar uma equipe } \\
\text { permanente de poda }\end{array}$ & $\begin{array}{c}\text { Definir a equipe e realizar } \\
\text { treinamento }\end{array}$ & Fevereiro & $\begin{array}{l}\text { SEAGRIMA e EMATER- } \\
\text { ASCAR/RS } \\
\text { OK }\end{array}$ \\
\hline $\begin{array}{c}\text { Divulgar e informar a } \\
\text { comunidade sobre boas } \\
\text { práticas na arborização } \\
\text { urbana. }\end{array}$ & $\begin{array}{c}\text { Montar a Cartilha da } \\
\text { Arborização Urbana de } \\
\text { Agudo } \\
\text { Divulgar o andamento das } \\
\text { ações na imprensa local }\end{array}$ & $\begin{array}{l}\text { Formatação e impressão } \\
\text { gráfica. } \\
\text { Matérias e entrevistas na } \\
\text { imprensa }\end{array}$ & $\begin{array}{c}\text { SEAGRIMA } \\
\text { Não realizado } \\
\text { OK }\end{array}$ \\
\hline
\end{tabular}

A construção de um Plano de Arborização, cujo resultado afetará grande parte da população do município, tem em sua premissa básica a participação desta população nas decisões de cunho não técnico. Nesse sentido a consulta pública realizada em 23 de março de 2010 propiciou aos agudenses conhecer o esboço do Plano de Arborização Urbana, opinar sobre seu planejamento e definir as áreas ou ruas da cidade onde seria realizado prioritariamente o plantio das árvores (tendo em vista o plantio gradual das mesmas) e votaram nas espécies para uso na arborização, conforme levantamento técnico.

Abaixo,o modelo da cédula de votação e a tabulação dos resultados:

Plano de Arborização Urbana de Agudo

Consulta Pública - dia 23/03/2010 
PAUL et al., v(5), n5, p. 783 - 791, 2012.

Revista Eletrônica em Gestão, Educação e Tecnologia Ambiental

REGET/UFSM (e-ISSN: 2236-1170).

Escolha das prioridades de espécies para passeios públicos (calçadas):

ENTRE PARÊNTESES ESTÁ O № DE VOTOS QUE CADA ESPÉCIE OBTEVE:

\begin{tabular}{|c|c|c|}
\hline FIAÇÃO BAIXA & FIAÇÃO ALTA & SEM FIAÇÃO \\
\hline ( 7) Calistemon-imperial & ( 12 ) Carvalhinho & $\begin{array}{l}\text { ( } 12 \text { ) Canforeira } \\
\text { 3o lugar }\end{array}$ \\
\hline $\begin{array}{l}\text { ( } 15 \text { ) Camboim(folha larga) } \\
\text { 3o lugar }\end{array}$ & ( 3 ) Ficus & ( 7 ) Chal-chal \\
\hline $\begin{array}{l}\text { ( } 21 \text { ) Extremosa-branca E ROSA } \\
\text { 10 lugar }\end{array}$ & (10) Manduirana & ( 3 ) Ipê-amarelo \\
\hline (4) Guamirim & $\begin{array}{l}\text { ( } 17 \text { ) Quaresmeira } \\
\text { 19 lugar }\end{array}$ & ( 11 ) Ipê-roxo \\
\hline ( 6 ) Mimo-de-vênus & $\begin{array}{l}\text { ( } 15 \text { ) Tarumã-sem-espinho } \\
\text { 3o lugar }\end{array}$ & $\begin{array}{l}\text { ( } 23 \text { ) Pau-ferro } \\
\text { 19 lugar }\end{array}$ \\
\hline $\begin{array}{l}\text { ( } 18 \text { ) Pitangueira } \\
\text { 20 lugar }\end{array}$ & $\begin{array}{l}\text { (16) Guabiroba-miúda } \\
\text { 2o lugar }\end{array}$ & $\begin{array}{l}\text { ( } 15 \text { ) Sibipiruna } \\
\text { 20 lugar }\end{array}$ \\
\hline
\end{tabular}

Abaixo,segue quadro com a caracterização das espécies eleitas pela população:

Quadro 2. Caracterização das espécies escolhidas para plantio na área urbana

\begin{tabular}{|c|c|c|}
\hline & Espécie & Principais Características \\
\hline \multirow[t]{3}{*}{$\begin{array}{l}\text { Árvores para } \\
\text { espaços com fiação } \\
\text { baixa }\end{array}$} & $\begin{array}{l}\text { Pitangueira } \\
\text { (Eugenia uniflora) } \\
\text { Família: Myrtaceae } \\
\text { Origem: Brasil }\end{array}$ & $\begin{array}{l}\text { Arbusto ou arvoreta, de } 3 \text { a } 15 \text { m de altura. Suas folhas são } \\
\text { simples, opostas, inteiras, brilhantes, subcoriáceas e } \\
\text { parcialmente caducas por ocasião do aparecimento das flores. } \\
\text { As flores são brancas. Os frutos são bagas globosas de } \\
\text { coloração vermelho-escura, com superfície lisa. A floração } \\
\text { ocorre geralmente de agosto a novembro, às vezes é alterada } \\
\text { pelo regime das chuvas e, a frutificação nos meses de } \\
\text { novembro a janeiro. A espécie apresenta também variação da } \\
\text { época de floração, nas diferentes regiões de ocorrência. }\end{array}$ \\
\hline & $\begin{array}{l}\text { Extremosa } \\
\text { (Lagerstroemia indica) } \\
\text { Família: } \quad \text { Lythraceae } \\
\text { Origem: Ásia }\end{array}$ & $\begin{array}{l}\text { Arvoreta de até } 6 \mathrm{~m} \text { de altura, com tronco liso marmorizado. As } \\
\text { flores desabrocham em cachos nas pontas dos ramos, em cores } \\
\text { róseas, lilás, carmim ou branca. Floresce no verão, à pleno sol. } \\
\text { Por seu pequeno porte, vai bem até em jardins pequenos e na } \\
\text { arborização urbana. }\end{array}$ \\
\hline & $\begin{array}{l}\text { Camboim } \\
\text { (Myrciaria } \\
\text { Família: Myrtaceae } \\
\text { Origem:Brasil. }\end{array}$ & $\begin{array}{l}\text { Arvoreta com } 6 \text { m de altura. Tronco tortuoso, com casca lisa. A } \\
\text { floração ocorre nos meses de novembro/dezembro. As folhas } \\
\text { são simples e semidecíduas. Cresce nas bordas das matas, nas } \\
\text { matas ciliares e capões situados em solos de maior umidade. }\end{array}$ \\
\hline
\end{tabular}


PAUL et al., v(5), n5, p. 783 - 791, 2012.

Revista Eletrônica em Gestão, Educação e Tecnologia Ambiental

REGET/UFSM (e-ISSN: 2236-1170).

\begin{tabular}{|c|c|c|}
\hline \multirow[t]{3}{*}{$\begin{array}{l}\text { Árvores para } \\
\text { Espaços com } \\
\text { Alta }\end{array}$} & $\begin{array}{l}\text { Tarumã } \\
\text { (Vitex montevidensis) } \\
\text { Família: Verbenaceae } \\
\text { Origem: Brasil }\end{array}$ & $\begin{array}{l}\text { Árvore de pequeno a médio porte, entre } 8 \text { e } 15 \text { metros de } \\
\text { altura. Flores brancas. Fruto redondo, com uma polpa branca } \\
\text { que envolve as sementes, de sabor adocicado. Sementes de } \\
\text { cor marrom claro. Fruto muito procurado pela fauna. } \\
\text { Melífera. Floresce em Dezembro. Frutos maduros de Janeiro a } \\
\text { Fevereiro. }\end{array}$ \\
\hline & $\begin{array}{l}\text { Guabirobeira } \\
\text { (Campomanesia } \\
\text { guaviroba) } \\
\text { Família: Myrtaceae } \\
\text { Origem: Brasil }\end{array}$ & $\begin{array}{l}\text { Árvore de pequeno a médio porte, } 5 \text { a } 8 \text { metros de altura. } \\
\text { Folhas simples, } 5 \text { a } 6 \mathrm{~cm} \text {. Frutos com } 2 \mathrm{~cm} \text {, redondos, amarelos } \\
\text { quando maduros, superficie lisa, comestivel, sabor um pouco } \\
\text { ácido. } 4 \text { a } 6 \text { sementes por fruto, envoltas em polpa amarela. } \\
\text { Germina facilmente, desenvolvimento normal. Atrativa a } \\
\text { fauna, e comestivel. Melifera. Floresce em Setembro, frutos em } \\
\text { Dezembro a Janeiro. }\end{array}$ \\
\hline & $\begin{array}{l}\text { Quaresmeira } \\
\text { (Tibouchina granulosa) } \\
\text { Família botânica: } \\
\text { Melastomataceae } \\
\text { Origem: Brasil }\end{array}$ & $\begin{array}{l}\text { Pode crescer até os } 12 \mathrm{~m} \text { de altura, e seu tronco pode atingir } 40 \\
\mathrm{~cm} \text { de diâmetro. Apresenta flores com tonalidades que vão do } \\
\text { rosa ao roxo, com grande potencial para ser utilizada como } \\
\text { planta ornamental, principalmente em floração, por isso é } \\
\text { recomendável em projetos paisagísticos, bem como na } \\
\text { arborização de ruas estreitas e sob redes elétricas. }\end{array}$ \\
\hline \multirow[t]{3}{*}{$\begin{array}{l}\text { Árvores para } \\
\text { Espaços sem Fiação }\end{array}$} & $\begin{array}{l}\text { Sibipiruna } \\
\text { (Caesalpinia pluviosa) } \\
\text { Família botânica: } \\
\text { Leguminosae } \\
\text { Origem: Brasil }\end{array}$ & $\begin{array}{l}\text { Chega a medir } 10 \text { metros de altura. A floração ocorre entre } \\
\text { setembro a novembro e produz flores amarelas organizadas em } \\
\text { cachos. A Esta espécie de árvore, que costuma viver por mais } \\
\text { de um século, é muito confundida com o pau-brasil e o pau- } \\
\text { ferro, pela semelhança da folhagem. A sibipiruna perde } \\
\text { parcialmente suas folhas no inverno e a floração ocorre de } \\
\text { setembro a novembro, com as flores amarelas dispostas em } \\
\text { cachos cônicos e eretos. }\end{array}$ \\
\hline & $\begin{array}{l}\text { Pau-ferro } \\
\text { (Caesalphinea ferrea) } \\
\text { Família botânica: } \\
\text { Leguminosae } \\
\text { Origem: Brasil }\end{array}$ & $\begin{array}{l}\text { Árvore muito utilizada em paisagismo urbano, tem o tronco } \\
\text { característico, liso e branco com manchas (marmorizado). } \\
\text { Propicia boa sombra e desenvolvimento rápido. Folhas } \\
\text { compostas, pinadas, } 5 \text { folíolos de até } 20 \mathrm{~cm} \text {. Flores amarelas, } \\
\text { pequenas, em cacho. Fruto em forma de vagem achatada de } \\
\text { casca dura, sendo que para extrair as sementes }(0,7 \mathrm{~cm} \text {, pretas) } \\
\text { é necessário quebrar com martelo. }\end{array}$ \\
\hline & $\begin{array}{l}\text { Canforeira } \\
\text { (Cinnamomum camphora } \\
\text { Família: Lauraceae } \\
\text { Origem: China e Japão. }\end{array}$ & $\begin{array}{l}\text { A canforeira tem uma floração primaveril de cor creme. São } \\
\text { cachos de pequenas flores com cerca de } 8 \mathrm{~cm} \text { de comprimento. } \\
\text { Uns pequenos e bonitos frutos negros, do tamanho de uma } \\
\text { ervilha seguem a floração. Esta árvore deve plantar-se, de } \\
\text { preferência nas regiões de clima ameno. Da sua folhagem e da } \\
\text { madeira extrai-se a cânfora. }\end{array}$ \\
\hline
\end{tabular}

Em 2011, no mês de março, foi realizada uma reunião de avaliação e planejamento anual, cujas ações são descritas no quadro abaixo: 
PAUL et al., v(5), n5, p. 783 - 791, 2012.

Revista Eletrônica em Gestão, Educação e Tecnologia Ambiental

REGET/UFSM (e-ISSN: 2236-1170).

Quadro 2. Cronograma de ações para o ano de 2011.

\begin{tabular}{|l|l|l|}
\hline AçõES PLANEJADAS & PERíODO / Prazo limite & Situação \\
\hline $\begin{array}{l}\text { Produção de Cartilha da Arborização Urbana de Agudo - } \\
\text { distribuição: } 1 \text { por família urbana }\end{array}$ & $\begin{array}{c}\text { Obril/2011 } \\
\text { exemplares }\end{array}$ \\
\hline $\begin{array}{l}\text { Levantamento do número e espécies arbóreas a serem plantadas } \\
\text { nos trechos restantes da Avenida Concórdia, Rua Barão do Rio } \\
\text { Branco e Rua Floriano Zurowski - conforme consulta pública. }\end{array}$ & Março/2011 & $\begin{array}{l}\text { Ok - } 110 \text { mudas } \\
\text { necessárias. }\end{array}$ \\
\hline Aquisição de mudas destinadas a arborização & Maio/2011 & Ok \\
\hline Aquisição de tela soldável para proteção das mudas & Abril/2011 & Ok \\
\hline Preparo das covas para os plantios & Junho/julho 2011 & OK \\
\hline Plantio das mudas (2010) & Julho/Agosto 2011 & OK \\
\hline Replantio das mudas (2010) & Agosto 2011 & OK \\
\hline Poda da vegetação arbustiva/arbórea & Abril/Maio 2011 & Ok \\
\hline
\end{tabular}

Em 2010, a Secretaria da Agricultura e Meio Ambiente, com apoio da Secretaria de Obras e Trânsito,realizou o plantio de 70 mudas em trechos da Rua Voluntário da Pátria e Avenida Concórdia. O custo direto (sem contar a mão-de-obra) da implantação de uma muda foi de R\$ 90,00 (muda+proteção de metal). As mudas possuem aproximadamente 2 metros de altura e a proteção metálica 1,5 metros,o que garante a proteção da mesma e a liberdade da copa para seu desenvolvimento.

Em 2011, o plantio superou as 110 espécimes inicialmente previstas. Devido à qualidade das mudas, somente 06 unidades tiveram de ser replantadas em 2010 devido ao ataque de formigas. Em 2011 houveram 2 casos de vandalismo com quebra da copa das mudas. A avaliação da equipe responsável pelo plano é positiva, visto o número diminuto de casos onde deve haver algum tipo de intervenção.

Abaixo, um breve relatório fotográfico de algumas das ações dos anos de 2010 e 2011.

Figura 1. Problemas no manejo da arborização urbana - poda radical

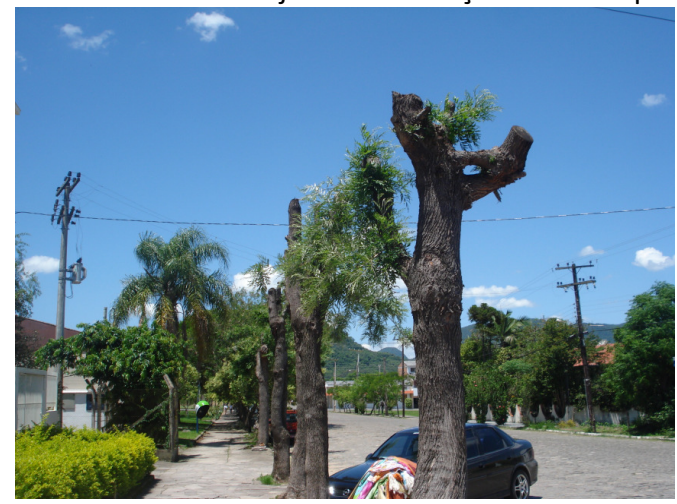

Fonte: Depto. de Meio Ambiente - Prefeitura de Agudo/RS 
PAUL et al., v(5), n5, p. 783 - 791, 2012.

Revista Eletrônica em Gestão, Educação e Tecnologia Ambiental

REGET/UFSM (e-ISSN: 2236-1170).

Figura 2. Calçadas levantadas - espécie não indicada para passeio público ou sem espaço para crescer

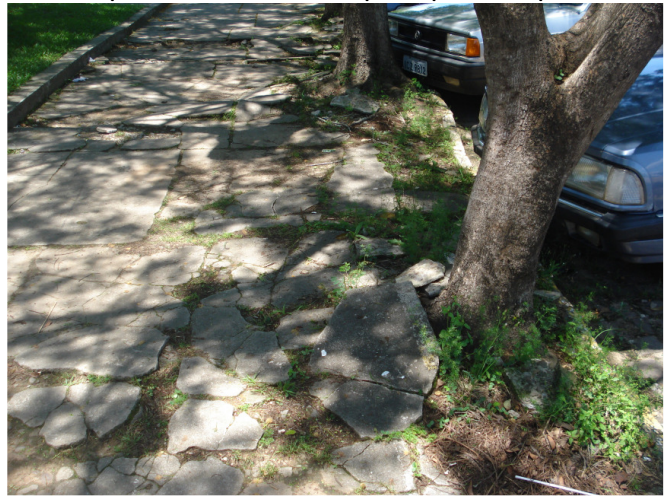

Fonte: Depto. de Meio Ambiente - Prefeitura de Agudo/RS

Figura 3. Espécie não indicada em passeios com fiação baixa

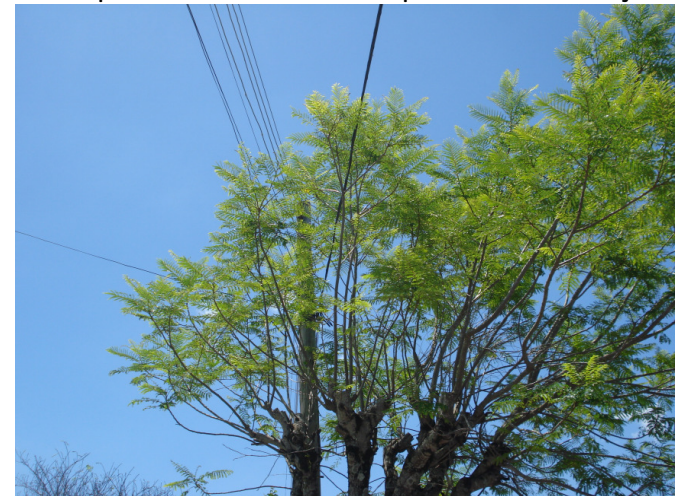

Fonte: Depto. de Meio Ambiente - Prefeitura de Agudo/RS

Figura 4. Plantio das mudas em 2010: espécie correta, tamanho da cova adequado e substrato de qualidade.

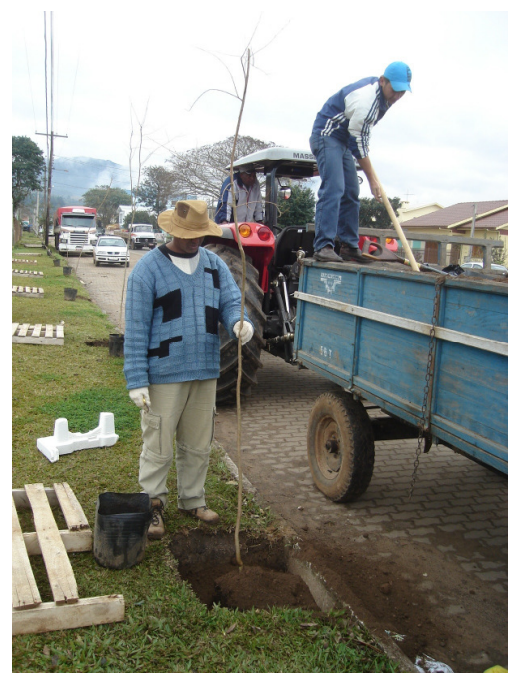

Fonte: Depto. de Meio Ambiente - Prefeitura de Agudo/RS 
PAUL et al., v(5), n5, p. 783 - 791, 2012.

Revista Eletrônica em Gestão, Educação e Tecnologia Ambiental

REGET/UFSM (e-ISSN: 2236-1170).

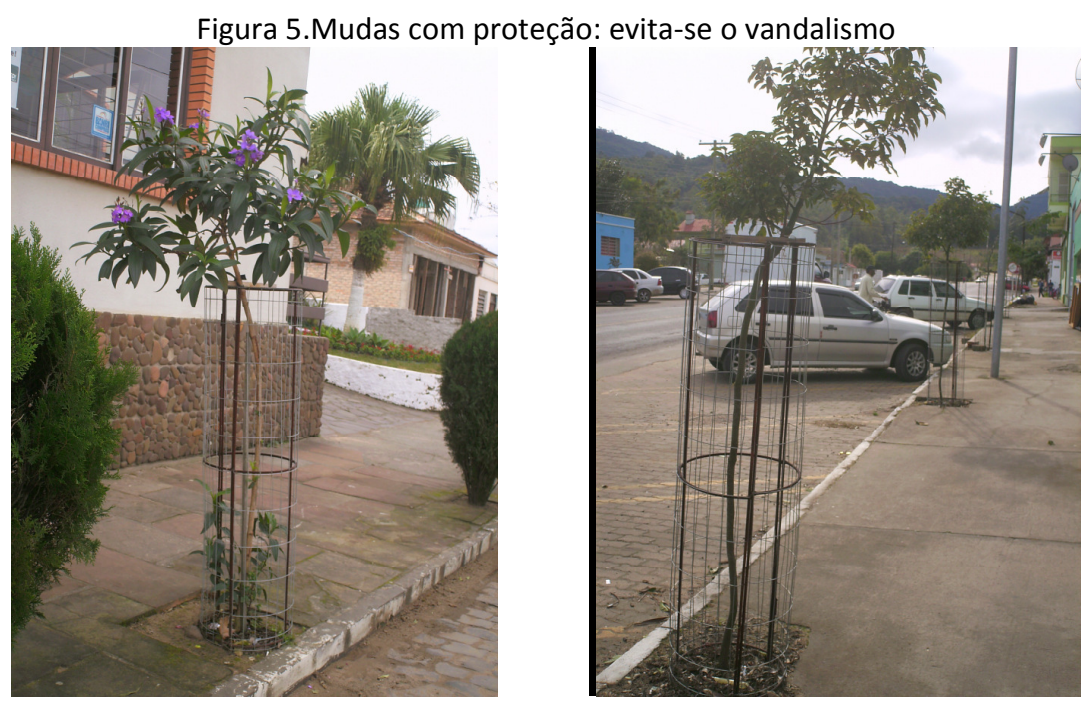

Fonte: Depto. de Meio Ambiente - Prefeitura de Agudo/RS

\section{Conclusão}

O Plano Municipal de Arborização Urbana de Agudo é uma ação continuada, aceita pela população e que gerou internamente no âmbito do poder público municipal uma nova visão sobre a importância do patrimônio arbóreo urbano. A demarcação dos locais de plantio e determinação da espécie pela equipe técnica foi realizada com a presença dos proprietários das casas e estabelecimentos comerciais onde seria realizado o plantio. Este contato foi de fundamental importância, pois os cidadãos sentiam-se comprometidos com o cuidado e manutenção das árvores. Externavam sua opinião e satisfação com o projeto e tiravam dúvidas diversas sobre o comportamento das espécies (se forneciam sombra, levantavam calçadas ou invadiam tubulações). Por serem mudas de crescimento adiantado, tanto as plantadas no ano de 2010 quanto às plantadas em 2011 já frutificaram (pitangueiras e cambuins) ou deram flores (quaresmeiras e extremosas). Ver o resultado mais imediato fez com que grande parte da população que mora em áreas não definidas como prioritárias procurassem o Departamento de Meio Ambiente solicitando plantio também em suas ruas.

Finalmente, o grande desafio da administração pública municipal para os próximos anos é captar recursos externos para viabilizar a implantação da arborização em um percentual maior da área urbana, finalizando no menor tempo possível o plantio, restando somente a manutenção com poda de condução. 


\section{Bibliografia}

AGUDO. Lei Municipal n.o 1.576/2004. Estabelece normas de manejo, proteção e conservação da arborização urbana no Município de Agudo e dá outras providências. Disponível em: http://www.camaraagudo.rs.gov.br/leis/legislacao-municipal/. Acesso em 15/07/2011.

AGUDO. Decreto 099/2005. Regulamenta a Lei Municipal n.o 1.576/2004, que estabelece normas de manejo, proteção e conservação da arborização urbana no Município de Agudo. Disponível em:

http://www.camaraagudo.rs.gov.br/leis/legislacao-municipal/. Acesso em 15/07/2011.

BONONI, V. L. R. Controle Ambiental de Áreas Verdes. Barueri, SP, 2004.

CONDESUS/UFSM. Planejamento Ambiental da Quarta Colônia: Diagnóstico do Município de Agudo. 2009; 213p. 